NOTICE: This is the author's version of a work that was accepted for publication in the journal Nurse Education Today. Changes resulting from the publishing process, such as editing, corrections, structural formatting, and other quality control mechanisms may not be reflected in this document. Changes may have been made to this work since it was submitted for publication. A definitive version was subsequently published in Nurse Education Today, [32(8), November 2012] doi:10.1016/j.nedt.2011.09.016

\title{
PROMOTING INFORMATION LITERACY THROUGH COLLABORATIVE SERVICE LEARNING IN AN UNDERGRADUATE RESEARCH COURSE
}

Robert Janke. MLIS

Learning Services Librarian

University of British Columbia Okanagan Library

3333 University Way

Kelowna, BC, Canada, V1V 1V7

robert.janke@ubc.ca

Barbara Pesut. PhD, RN

Assistant Professor of Nursing

Canada Research Chair, Health, Ethics and Diversity

Faculty of Health and Social Development

University of British Columbia Okanagan

AS 286, 3333 University Way

Kelowna, BC, Canada, V1V 1V7

barb.pesut@ubc.ca

Lynnelle Erbacker

Graduate Nurse

University of British Columbia Okanagan

3333 University Way

Kelowna, BC, Canada, V1V 1V7

lynnelle.erbacker@ubc.ca

Word count:

3223

Keywords:

Baccalaureate nursing students; Interprofessional relations; Evidence-based practice; Information literacy 


\title{
PROMOTING INFORMATION LITERACY THROUGH COLLABORATIVE SERVICE LEARNING IN AN UNDERGRADUATE RESEARCH COURSE
}

\begin{abstract}
$\underline{\text { ABSTRACT }}$
Information literacy is an important foundation for evidence-based nursing practice. Librarians, the experts in information literacy, are important collaborators in the process of teaching nursing students information literacy skills. In this article we describe a service learning project, offered in a third year nursing research course, designed to teach information literacy and to enhance students' appreciation of the role of evidence in nursing practice. Students worked in groups, and under the guidance of a nursing instructor and librarian, to answer a question posed by practicebased partners. Through the project students learned essential skills of refining a question, identifying systematic search strategies, gleaning essential information from a study and using a bibliographic management tool. Evaluation of the project indicated that although the project was challenging and labour intensive students felt they learned important skills for their future practice. Several recommendations for further enhancing the collaboration are made.
\end{abstract}




\section{INTRODUCTION}

Nursing research may well be the most unpopular course in the curriculum for students to take and faculty to teach. Nursing faculty who teach nursing research know firsthand the feelings that arise in the middle of a semester as they struggle to make the course relevant. Students often feel the course is designed to test their patience rather than their nursing abilities. Probably the greatest challenge with teaching nursing at the undergraduate level is helping students see the relevance of the course to their nursing practice (Halcomb \& Peters, 2009). Part of the problem may be the lack of clarity about the goals of an undergraduate research course. Although there is common agreement that a basic familiarity with the language and process of research is necessary, the assignments reflect changing ideas about the level of competence required at the undergraduate level. For example, many assignments focus on research critique. Yet, critiquing research requires a sophisticated knowledge of the content. Other assignments require students to engage in the process of research. However, the level of rigor achieved in conducting research at the undergraduate level belies the difficulties of knowledge construction.

An important goal for an undergraduate nursing research course is to assist students to engage in evidence-based practice (EBP). An important pre-requisite of EBP is developing information literacy (Barnard et al., 2005; Shorten et al., 2001), which according to the American Library Association (1989), is the ability to recognize when information is needed and have the ability to locate, evaluate, and use it effectively. Prior to evaluating the evidence itself, nursing students need to have the ability to confidently and accurately search the databases in which the evidence resides.

This being said, nurse educators often do not think of librarians when they think of collaborating with a campus partner to teach information literacy. One of the reasons may be that 
the University hierarchy tends not to see librarians as equal to teaching faculty (Albitz, 2007). A recent survey found that only 14 of $106(13 \%)$ nursing faculty specifically mentioned instruction in response to a question asking them what collaboration with a librarian meant to them (Schulte \& Sherwill-Navarro, 2009). However, the greater emphasis on EBP in the field of nursing had greatly $(24.1 \%)$ or somewhat $(36.1 \%)$ increased the willingness of respondents to have a librarian present at an instructional session (Schulte \& Sherwill-Navarro, 2009). Some have suggested that there is a need to restructure the relationship between nurse educators and librarians (Barnard et al., 2005). Miller et al., (2010) encourage both librarians and educators to come out of their professional information silos and to work together to identify the unique expertise that each possess to develop a successful learning experience for students.

A number of authors have described innovative pedagogical techniques for nursing research courses. For example, Poston (2002) described a learner-centered approach where students were allowed to select both a desired grade and the types of projects required to earn that grade. Projects included research critiques, poster presentations, research conference attendance, research assistant experiences, and research utilization papers. A number of articles have described the use of clinically-based research projects designed to bridge theory and practice and to enhance evidence-based practice (e.g. August-Brady, 2005; Clark et al., 2009; Kenty, 2001; Meeker et al., 2008). De Cordova et al., (2008) described an innovative project where students and clinicians were brought together in teams, provided a common course on assessing evidence, and participated in implementing and evaluating an evidence-based practice change. Kennel et al., (2009) detailed a project whereby they paired 36 students with clinical nurse researchers who were working on 20 research projects in various stages of completion. The experiences encompassed a range of activities, from helping with literature reviews, to data 
collection, to helping with the dissemination of findings. In a small undergraduate honours class Rash (2005) paired students with community partners to develop a research proposal that would benefit their community partner. These innovations typically introduce students to various aspects of research while creating stronger ties to clinical practice.

\section{THE ASSIGNMENT}

Recognizing the difficulties in teaching undergraduate nursing research we sought to design a project, facilitated by a nurse and a librarian that would enhance students' information literacy and their appreciation of the relevance of empirical evidence for practice. The scope of the project was based upon the assumption that although a sophisticated critique of research may not be a realistic or necessary undergraduate competency (much of that having already been accomplished through the peer-review process of publishing), the ability to obtain and synthesize literature is critical for a nurse who is committed to life-long learning. Further, we wanted the learning to be closely connected to the practice environment. The result was a service learning project where students worked in groups to conduct a literature review in response to a question generated by clinicians in practice. However, we were cautious and transparent with our clinical partners about the limitations of the review in that it was neither comprehensive nor critical. We did have students include the method of their search strategy and a table of the details of the studies reviewed. In this way our clinical partners could evaluate the extent of the review and conduct their own critical analysis.

We began by contacting the research coordinator of the health authority in which the students practiced. An email query resulted in over 35 topics generated by nurses, physicians, social workers and recreational therapists. Students, working in groups, selected the questions that interested them. Each group selected a leader, and this leader was responsible for being a 
liaison to the clinical partner. This partnering was mutually beneficial; students were responsible for providing a service and clinical partners were grateful for that service in light of their own limited time and resources.

A critical aspect of the assignment was breaking it down into achievable steps which included the following: (1) organizing into groups and writing a group accountability contract; (2) clarifying the research question; (3) learning to use the bibliographic tool RefWorks; (4) designing a literature search strategy that included specifying the databases and search terms; (5) completing the search and downloading the articles into the bibliographic management tool; (6) searching reference lists manually; (7) selecting the articles and recording important data from the articles onto a table that included author(s), objectives, study design, sample and sampling method, intervention (if applicable), setting, main variables and measures, results, and conclusions; (8) writing up the findings and conclusions based upon the literature review; (9) submitting the paper for grading; (10) revising the paper according to instructor feedback and submitting it to the clinical partners; and (11) evaluating individual participation based upon the agreements made in the group contract.

Students were required to submit each step of the assignment at designated time throughout the semester for feedback. This process helped to ensure that students felt supported in the learning process and that they would not miss critical steps that would affect the quality of the review. To ensure that students did polish and submit their work, they were not assigned a grade until the work was revised according the instructor feedback and submitted to the clinical partner. Submitting the paper for grading prior to sending it to clinical partners also helped provide students and faculty with confidence about the quality of the work. The following is a 
description of the strengths and areas for improvement in the assignment from the perspectives of the learning partners.

\section{THE STUDENT PERSPECTIVE}

Students were required to submit feedback on the assignment that entailed answering questions such as: Was it useful? How difficult was it? Where did you have challenges? What did you learn from it? What would you change? The feedback was required of each student and was submitted through the course management system separately from the assignment so that the instructor would not be influenced by student perceptions of the assignment when grading. Students provided candid responses. The following is a summary of the student comments. The major challenges were related to the nature of the group work and the level of difficulty of the project. For many, the most frustrating part of the assignment was the group work. Frustrations included the different work habits of students in the group, difficulties in scheduling and the amount of conflict resolution required. The fact that students were producing work for clinical partners increased the level of accountability and subsequent stress. For some students, working alongside potential future employers and coworkers was intimidating. Many of the questions posed by their clinical partners were ones that the clinical partners were having difficulty finding literature for, and hence, they were particularly challenging for students to answer. For example, some clinicians were interested in best practices around highly specialized treatments or procedures and from our review it appeared that little had been done in these areas. However, it was these same frustrations that contributed to the students' personal development and provided them with skills that will be useful in future. Some students suggested that through the difficulties of group work they were able to learn strategies to aid them in more successful team work. 
Developing the academic skills needed to complete a literature review of this magnitude was overwhelming for many of the students. Although these were third year students, this was the first paper of this kind the students had been assigned. Particular challenges arose around searching databases for relevant articles and summarizing the pertinent information once found. In the end, however, students were proud of the work they had done, and spoke of the many skills they had learned through the process. Areas in which students gained confidence included, using tools such as RefWorks and MeSH search strategies; APA formatting; reading, understanding, and evaluating scholarly research articles; and most importantly, learning how to apply the research to practice areas. Many attributed the success of the project to the support given to them by both the professor and librarian involved, as well as the step-by-step lay out of the review.

The student consensus on the project was that although at times the learning was intense, it built professional proficiency. Students wrote of their increased appreciation for evidencebased practice and their ability to bring this knowledge into their own practice. Overall, the project was seen as a challenging and enlightening experience.

\section{INFORMATION LITERACY INSTRUCTION}

The Library provides an instruction session to every incoming student as part of their required English classes. Currently, these sessions are part online tutorial and part in-class lecture. Students enrolled in the nursing program receive an additional session in the first term of their first year that provides an introduction to searching the Cumulated Index to Nursing and Allied Health Literature (CINAHL) index and locating resources. Unfortunately, there is no formal library instruction in the second year of the nursing program. As a result, by the time 
nursing students reach third year, and the project outlined in this paper, their ability to search for and assess information tends to be fairly disparate.

For this learning project, once students had selected their question the librarian presented a hands-on 75 minute information literacy class focused on searching for and retrieving research evidence. Key resources covered included PubMed and CINAHL. Linking terms and/or phrases together through Boolean operators (AND, OR, \& NOT) which can narrow, broaden, and refine a search was one of the key skills taught. Time was also spent teaching the students how to incorporate controlled vocabulary such as MeSH into their search strategies. MeSH headings are applied to article records in PubMed in order to describe the article. Learning to use these hierarchically organized headings can improve search efficiently drastically as MeSH can account for variability and synonyms that occurs in natural language. Where possible, these skills were reinforced with active learning strategies. The class also included a short introduction to RefWorks, an online bibliographic manager that the Library licenses. RefWorks allows account holders to upload, store, organize, share, and format references easily. Students found the introduction to RefWorks particularly useful and suggested that this should be provided in the first year of the nursing program.

Outside of formal class time the librarian also held small seminars with 5 of the 27 groups. These volunteer seminars were proposed by the groups on their own accord and were focused on developing sound search strategies geared to their specific topics.

\section{THE LIBRARIAN PERSPECTIVE}

In light of the difficulties that some of the groups encountered in searching the literature, in future it would be important for all of the groups to have individualized help from the librarian. It would also be helpful to have the librarian involved in step four of the assignment - 
providing feedback to the students on database selection and search strategy formulation. This could be done through email, a face to face seminar, or discussion boards on a web-based course shell.

Through working with these groups that came for further assistance it became apparent that there was likely too much covered in the single session and that in future there should be more shorter classes. Authors have pointed out that it is increasingly apparent that students rarely gain the necessary skills and confidence in a single orientation (Carlock \& Anderson 2007; Leasure et al., 2009) and that there needs to be greater integration throughout the course material to successfully teach and reinforce critical literacy skills (Orr et al., 2001).

As the liaison librarian for the School of Nursing it has been a long standing goal of mine to increase the evidence-based practice skills of the nursing students. I was thrilled to be asked to participate in this assignment to the extent that I was. Too often, librarians are called in for the "one-shot" information literacy session that feels like a last minute addendum to the curriculum. I encourage all nursing faculty to reach out to their subject librarians in a meaningful course integrated way and I'm sure you will find a willing and eager co-instructor.

\section{THE INSTRUCTOR PERSPECTIVE}

Although I was pleased by the quality of the literature reviews and the learning that occurred, I was somewhat surprised by the workload, the intensity of the group dynamics, and the challenges students had refining their questions. Providing feedback on each step for 27 groups was labour intensive, particularly when it became apparent to me that I could not assume that students were familiar with accessing the literature. Even though students had been required in the first two years of their program to provide evidence-based articles for their assignments, I quickly realized that how they found these articles was more random than systematic. Indeed, I 
could not even assume that students were able to use controlled searching vocabulary or to differentiate theoretical from empirical articles.

Group dynamics were particularly challenging. As it turned out, these students were working on a number of group projects in other classes as well and so their workload was higher than normal. But beyond that, the high percentage of the overall mark assigned to this project $(60 \%)$ generated anxiety, particularly when some students in the group were satisfied with lower marks (and hence effort) than others. Despite the use of a group contract and extensive coaching on how to equitably divide the workload, many students felt that they were left to struggle on their own without the support of the group. In future, I would meet more frequently with the various groups, either on-line or in the classroom and ask explicitly about how the groups were working together. The fact that it was also a process assignment whereby students had to learn skills as they went along through the semester (as opposed to having all the skills up front as is typical to most assignments) further enhanced the anxiety. Students recommended that process pieces of the assignment (e.g. literature strategy, problem and purpose statement) be assigned marks along the way so that they would have tangible evidence of how they were progressing in relation to the task.

Identifying relevant literature to answer the clinical questions was particularly problematic in this assignment. In some cases there was simply no literature available, in other cases the question was so broad that there was an overwhelming amount of literature. This created frustration with the process as students had to go back and forth with the literature and refine the question according to what was available. It also meant the work required of the different groups was somewhat uneven. In future I would refine the questions according to the 
available literature prior to providing them to the students. This is an area for further collaboration with the librarian.

The most gratifying part of the project was receiving the thank you emails from the partners in practice. Many provided positive comments about the students' work and were grateful to have this resource available to them. For example, one clinical partner used the information provided to start a caregiver support group based upon the best available evidence and another revised a clinical procedure in the emergency department. One group summarized the best evidence around supervised injection facilities. This clinical partner appreciated the many important and nuanced factors that were included in the analysis, details that are often overlooked by those making the decision about whether these facilities are effective. Although some students felt intimidated by having to provide this level of expertise to clinical partners, many did not realize that the skills they learned through this process were ones that may not necessarily be held by their practice partners. They were making a valuable contribution as part of a true learning partnership.

\section{CONCLUSION}

Health information literacy is an essential skill for nursing students. Collaboration between nursing faculty and librarians provides strategic opportunities to enhance health information literacy through undergraduate nursing research courses. In this article we have described a service learning project guided by a nurse and a librarian designed to teach information literacy. In the future we hope to more formally assess the impact that this service learning approach has on the development or increasing of information literacy skills. Of further interest would be to situate it within other approaches that have been studied formally. Although the learning was at times intense during this project, the consensus from all learning partners was 
that students had learned important and relevant strategies for supporting evidence-based practice. 


\section{$\underline{\text { REFERENCES }}$}

Albitz, R. S., 2007. The what and who of information literacy and critical thinking in higher education. Portal: Libraries and the Academy 7 (1), 97-109.

American Library Association, Presidential Committee on Information Literacy, 1989. Final report. Retrieved from http://www.ala.org/ala/mgrps/divs/acrl/publications /whitepapers/presidential.cfm

August-Brady, M. M., 2005. Teaching undergraduate research from a process perspective. The Journal of Nursing Education 44 (11), 519-552.

Barnard, A., Nash, R., O'Brien, M., 2005. Information literacy: Developing lifelong skills through nursing education. The Journal of Nursing Education 44 (11), 505-510.

Carlock, D., Anderson, J., 2007. Teaching and assessing the database searching skills of student nurses. Nurse Educator 32 (6), 251-255

Clark, K., Stanforth, D., Humphries, M. P., 2009. Teaching undergraduate nursing research: A collaborative approach. Nurse Educator 34 (1), 9-11.

de Cordova, P. B., Collins, S., Peppard, L., Currie, L. M., Hughes, R., Walsh, M., Stone, P. W., 2008. Implementing evidence-based nursing with student nurses and clinicians: Uniting the strengths. Applied Nursing Research 21 (4), 242-245.

Halcomb, E. J., Peters, K., 2009. Nursing student feedback on undergraduate research education: Implications for teaching and learning. Contemporary Nurse 33 (1), 59-68.

Kennel, S., Burns, S., Horn, H., 2009. Stimulating student interest in nursing research: A program pairing students with practicing clinician researchers. Journal of Nursing Education 48 (4) 209-212. 
Kenty, J. R., 2001. Weaving undergraduate research into practice-based experiences. Nurse Educator 26 (4), 182-186.

Leasure, A. R., Delise, D., Clifton, S. C., Pascucci, M. A., 2009. Health information literacy: Hardwiring behavior through multilevels of instruction and application. Dimensions of Critical Care Nursing 28 (6), 276-282.

Meeker, M. A., Jones, J. M., Flanagan, N. A., 2008. Teaching undergraduate nursing research from an evidence-based practice perspective. The Journal of Nursing Education 47 (8), 376379.

Miller, L. C., Jones, B. B., Graves, R. S., Sievert, M. C., 2010. Merging silos: Collaborating for information literacy. Journal of Continuing Education in Nursing 41 (6), 267-272.

Orr, D., Appleton, M., Wallin, M., 2001. Information literacy and flexible delivery: Creating a conceptual framework and model. Journal of Academic Librarianship 27 (6), 457-463.

Poston, I., 2002. Stimulating enthusiasm for research in undergraduate nursing students. The Journal of Nursing Education 41 (4), 186-188.

Rash, E. M., 2005. Educational innovations. A service learning research methods course. Journal of Nursing Education 44 (10), 477-478.

Schulte, S. J., Sherwill-Navarro, P. J., 2009. Nursing educators' perceptions of collaboration with librarians. Journal of the Medical Library Association 97 (1), 57-60.

Shorten, A., Wallace, M. C., Crookes, P. A., 2001. Developing information literacy: A key to evidence-based nursing. International Nursing Review 48 (2), 86-92. 